\title{
Mikrostruktura i właściwości mechaniczne wielowarstwowych platerów na bazie Al i Ti wytwarzanych z wykorzystaniem energii wybuchu
}

\author{
Microstructure and mechanical properties of multi-layered $\mathrm{Al} / \mathrm{Ti}$ \\ composites produced by explosive welding
}

\section{Streszczenie}

W pracy analizowano zmiany mikrostrukturalne oraz formowanie się nowych faz w wielowarstwowych układach platerów zbudowanych na bazie Ti i Al. Wykorzystano techniki mikroskopii optycznej i skaningowej mikroskopii elektronowej, pomiary mikrotwardości, a także próbę zginania w warunkach udarowych. Obserwacje w skali makro pokazały, że w procesie spajania wytworzono 15-warstwowy plater wolny od nieciągłości strukturalnych. Powierzchnie połączenia uległy silnemu odkształceniu i wykazywały mieszany falisto-płaski charakter ze strefami przetopień preferencyjnie lokowanymi na grzbiecie oraz w zawinięciach fal. Zaobserwowano, że silnie pofalowane granice połączenia zawsze formowały się w warstwach położonych w pobliżu ładunku wybuchowego. Analizy w mikro skali udokumentowały występowanie cienkiej warstwy przetopionej o silnie rozdrobnionej strukturze.

Słowa kluczowe: spajanie wybuchowe; wielowarstwowe platery na bazie Ti i Al; strefy przetopień; transmisyjna i skaningowa mikroskopia elektronowa; mikrotwardość

\begin{abstract}
Microstructure and phase in the bonding zone of explosively welded Ti/Al multilayer clads were examined by optical microscopy and scanning electron microscopy. The defect-free multilayer composite was successfully formed. The macro-scale observations showed that the interfaces between joined plates presented mixed wavy/flat shape with solidified melt inclusions located preferentially at the crest of each wave and in the wave vortex. It was found that interfaces of wavy character were always formed in layers near the explosive charge and flattened with the increase of the distance from the top surface. The micro-scale analyses observations revealed a presence of very thin reaction layer at the flat parts of the joint plates and nano-grained structure of melted zones.
\end{abstract}

Keywords: explosive welding; Ti-Al multi-layered composite; melted zone; TEM and SEM; microhardness

\section{Wprowadzenie}

Wielowarstwowe kompozyty na bazie metali lekkich są w ostatnich latach przedmiotem silnego zainteresowania. Wynika to z faktu, że reprezentują pożądane połączenie ceny z wysoką wytrzymałością i sztywnością oraz doskonałą odpornością korozyjną w szerokim zakresie temperatury. Uzyskania poprawnego połączenia blach na bazie metali o silnie zróżnicowanych własnościach mechanicznych, fizycznych i chemicznych jest bardzo trudne lub wręcz niemożliwe z wykorzystaniem tradycyjnych technik spajania. W przypadku wyrobów warstwowych jedną z technik wytwarzania w skali przemysłowej pełnowymiarowych układów o charakterze kompozytu jest wykorzystanie technologii zgrzewania wybuchowego (EXW) [1]. Jedną z najbardziej istotnych zalet tej metody w odniesieniu do techniki walcowania/zgrzewania akumulacyjnego (ARB) [2] czy spajania pod wysokim naciskiem [3] jest to, że umożliwia ona bezpośrednie usuwanie tlenków z powierzchni połączenia. Obecność powierzchni rozdziału wolnej od tlenków odgrywa kluczową rolę w procesie migracji atomów poprzez granicę rozdziału oraz ułatwia

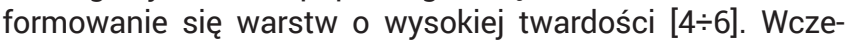
śniejsze prace ujawniły, że proces spajania wybuchowego układów wielowarstwowych stowarzyszony jest z wieloma zmianami mikrostrukturalnymi w pobliżu strefy połączenia. Charakter tych zmian silnie uzależniony jest od położenia płyty w układzie, ponieważ parametry procesu spajania zmniejszają się wraz z odległością od płyty lotnej. W konsekwencji prowadzi to do silnego zróżnicowania umocnienia poszczególnych warstw oraz ilości pojawiających się stref przetopień.

Prof. dr hab. inż. Henryk Paul, dr inż. Magdalena Miszczyk - PAN w Krakowie; dr Mariusz Prażmowski - Politechnika Opolska; mgr inż. Aleksander Gałka - ZTW Explomet.

Autor korespondencyjny/Corresponding author: m.prazmowski@po.opole.pl 
W pracy podjęto analizę zmian mikrostrukturalnych w strefach połączeń pomiędzy poszczególnymi warstwami. Zmiany te analizowano z wykorzystaniem technik transmisyjnej i skaningowej mikroskopii elektronowej, a także poprzez pomiar mikrotwardości oraz analizę zachowania w procesie udarowego zginania.

\section{Materiał i metodyka badawcza}

Proces spajania wybuchowego wielowarstwowych układów na bazie Ti i Al przeprowadzony został przez ZTW Explomet w Opolu. Układ równoległy złożony z 15 warstw spajano w „jednym akcie strzałowym", w którym płyty Al(AA1050) oraz Ti(Gr1) o grubości $1 \mathrm{~mm}$ ułożone były naprzemiennie, przy czym pierwszą i ostatnią warstwę stanowiła płyta Ti. Jako ładunek wybuchowy zastosowano zmodyfikowany Saletrol o zróżnicowanej grubości, co determinowało zróżnicowane prędkości detonacji w zakresie od $2300 \mathrm{~ms}^{-1}$ do $2600 \mathrm{~ms}^{-1}$. Schemat układu pokazano na rysunku 1. Mikrostrukturę analizowano na próbkach, które wycinano z początku, środka i końca płyty, a także ze zróżnicowanych położeń na grubości plateru.

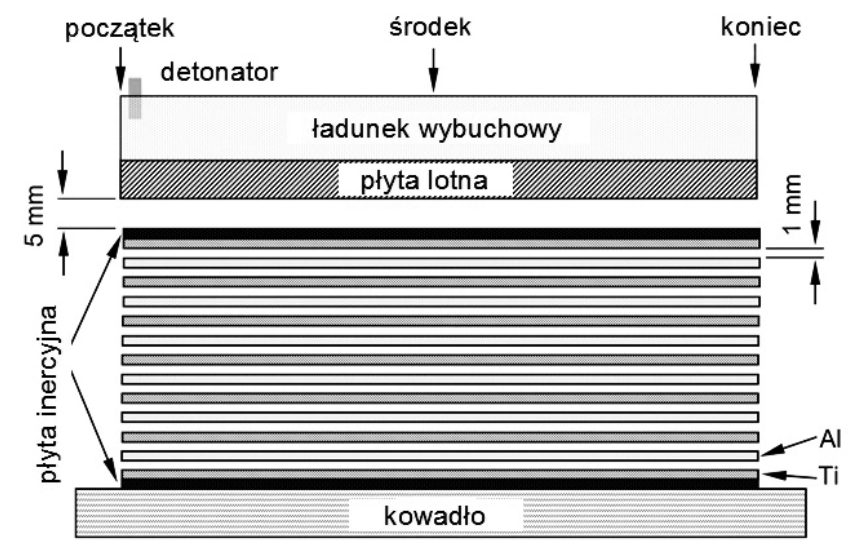

Rys. 1. Schemat procesu spajania układu wielowarstwowego z wykorzystaniem energii wybuchu

Fig. 1. Diagram of the bonding process of a multi-layer system using explosion energy

\section{Wyniki i dyskusja}

Charakterystyka strefy połączenia w makro-/meso- skali Zastosowane prędkości odkształcenia, $2200 \mathrm{~ms}^{-1}, 2400 \mathrm{~ms}^{-1}$ i $2600 \mathrm{~ms}^{-1}$ doprowadziły do uzyskania "poprawnie" połączonych układów platerów. Badania platerów z zastosowaniem SEM dokumentują, że w strefie połączenia nie obserwowano pęknięć ani nieciągłości. Obserwowano silne zróżnicowanie morfologii złącz zarówno wzdłuż, jak i na głębokości plateru (rys. 2). Takie zróżnicowanie obserwowano dla układów spajanych przy różnych prędkościach detonacji. We wszystkich analizowanych układach najsilniejsze „pofalowanie" granicy rozdziału występowało na początku plateru, pomiędzy pierwszą (Ti) i drugą (Al) płytą. Parametry fali ulegały systematycznemu zmniejszeniu wraz ze wzrostem odległości od punktu inicjacji. Dla pierwszej granicy rozdziału wysokość $(\sim 150 \mu \mathrm{m})$ i długość ( 300 $\mu \mathrm{m})$ fali zmniejszyła się do $50 \mu \mathrm{m}$ i 70 $\mu \mathrm{m}$ na końcu plateru. Pierwsza granica rozdziału zawierała także znaczną ilość dużych stref przetopień, które preferencyjnie lokowane były na grzbiecie oraz w zawinięciach fali, lub też jako "inkluzje" w warstwie Ti.

Dla granic rozdziału ulokowanych wśrodku (warstwa nr 7) oraz na spodzie (14) plateru obserwowano formowanie się cienkich warstw stref przetopień o grubości nieprzekraczającej $50 \mu \mathrm{m}$ (rys. 2). Najbardziej charakterystyczną cechą stref przetopień jest pojawienie się siatki mikro-/makro- pęknięć, propagujących prostopadle do granicy rozdziału, które jednak nie wykazują skłonności do propagacji do wnętrza łączonych płyt.

\section{Właściwości mechaniczne}

Rozkład mikrotwardości analizowano wzdłuż „linii skanowania" poprowadzonych poprzez 1, 7 i 14 granicę rozdziału na próbkach wyciętych z początku, środka i końca plateru (rys. 3). Średnia wartość mikrotwardości płyt w stanie wyjściowym, tj. przed procesem spajania wynosiła 165 HV i 35 HV odpowiednio dla Ti i Al. Po procesie EXW obserwowano silne zmiany mikrotwardości, w szczególności w płycie Ti, a zmierzone wartości zawierały się w granicach od 175 HV do 218 HV oraz 35 HV to 48 HV, odpowiednio dla Ti i Al. Nie zaobserwowano prostej relacji pomiędzy rozkładem mikrotwardości a odległością od powierzchni. W przypadku płyt Al rozkład mikrotwardości jest podobny dla wszystkich warstw, z wartościami na poziomie nieznacznie poniżej $40 \mathrm{HV}$. Wyjątkiem jest linia

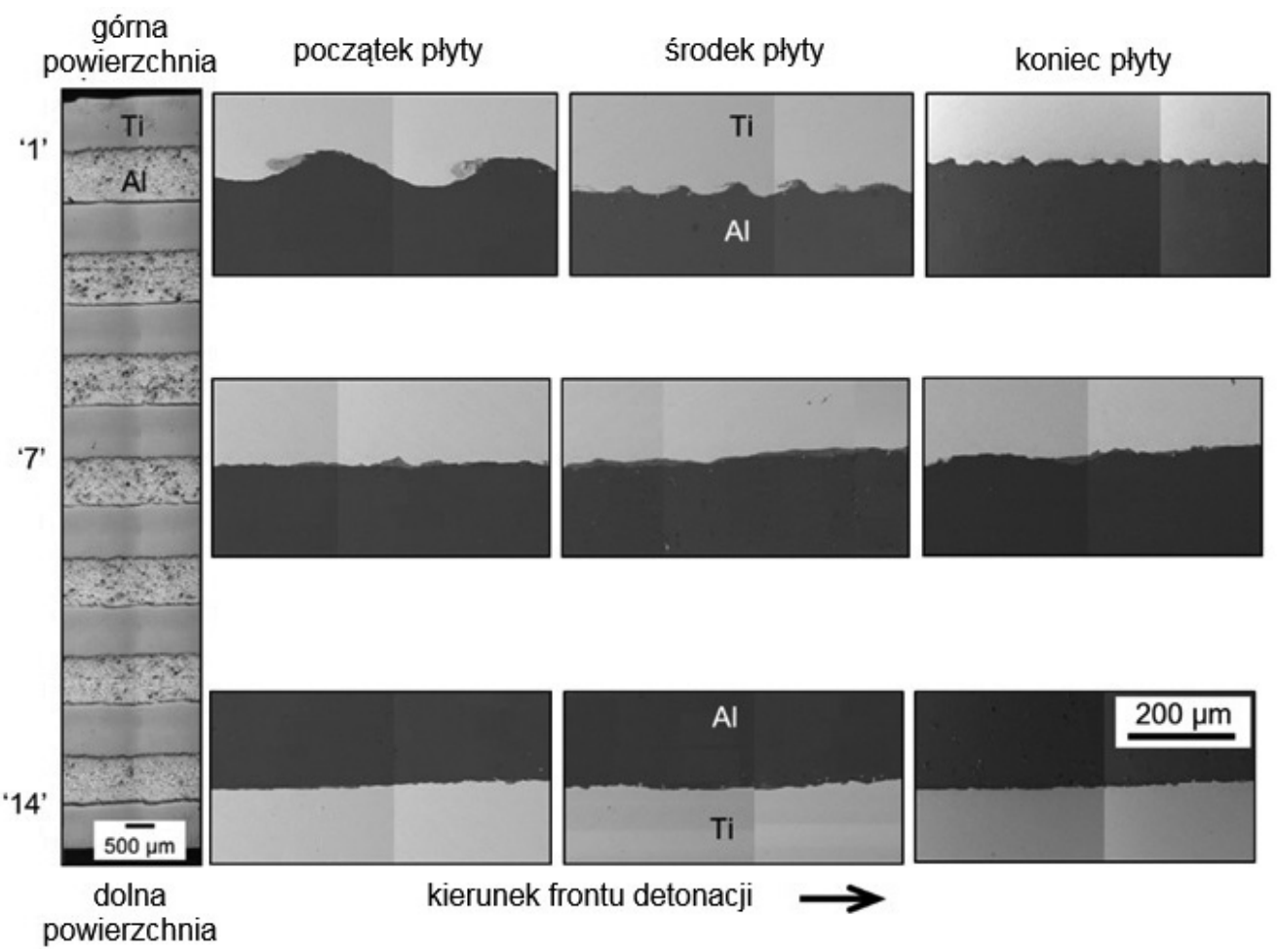

Rys. 2. Zmiany mikrostrukturalne na przekroju poprzecznym plateru dla próbek wyciętych z początku, środka i końca plateru Fig. 2. Microstructural changes on the cross-section of the plating for samples cut from the beginning, middle and end of the plating 
poprzez pierwszą granicę dla próbki wyciętej z początku plateru, gdzie wartości mikrotwardości zbliżone są do $48 \mathrm{HV}$. W przypadku płyt Ti odnotowano systematyczny wzrost twardości w pobliżu powierzchni, co prowadziło do charakterystycznego przebiegu zmian w kształcie litery "U”.

Test zginania w warunkach dynamicznych przeprowadzono w temperaturze 77 K, $293 \mathrm{~K}$ oraz $473 \mathrm{~K}$ z wykorzystaniem młota Charpy'ego na próbkach bez karbu. Dla zastosowanych warunków odkształcenia (energia młota $300 \mathrm{~J}$ ) zachowanie próbek było zasadniczo podobne, tzn. zewnętrzne blachy uległy pęknięciu, natomiast delaminację pomiędzy warstwami (innymi od zewnętrznych blach) obserwowano tylko w próbkach testowanych w $77 \mathrm{~K}$ oraz 293 K (rys. 4).
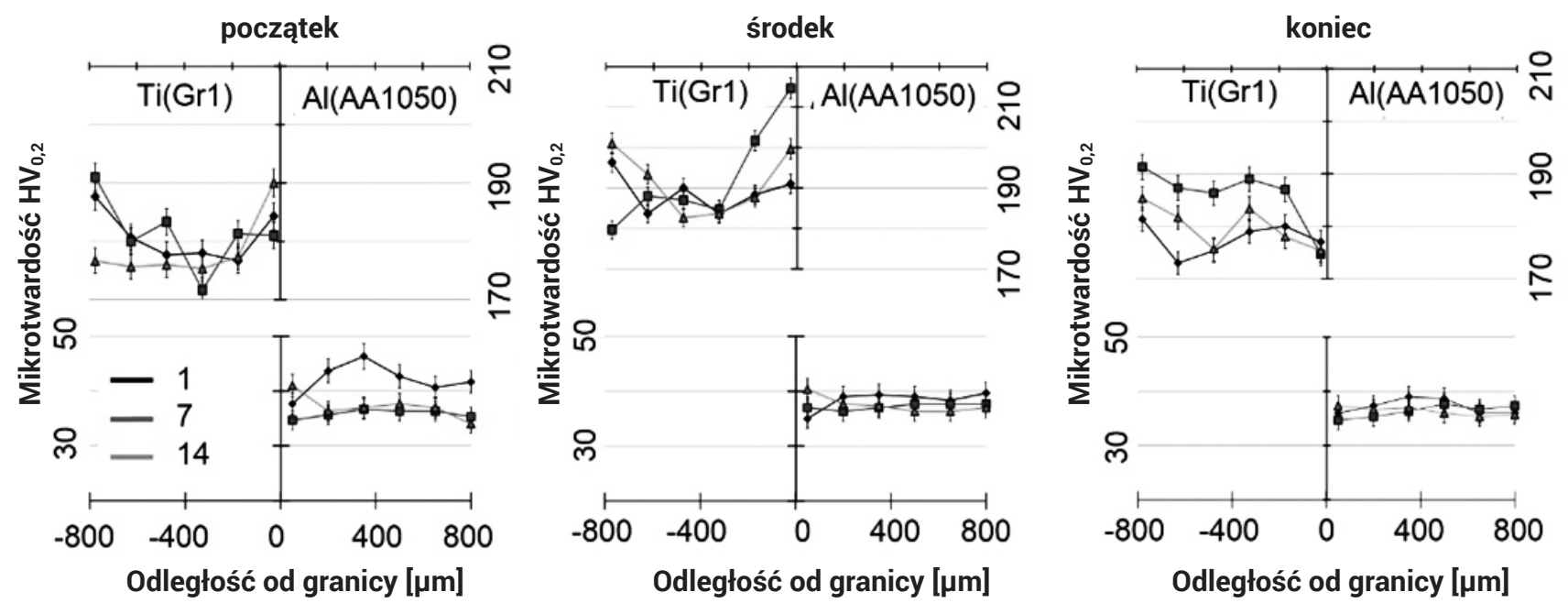

Rys. 3. Pomiary mikrotwardości wzdłuż linii skanowania poprzez granice rozdziału

Fig. 3. Measurements of microhardness along the scanning line through the separation boundaries

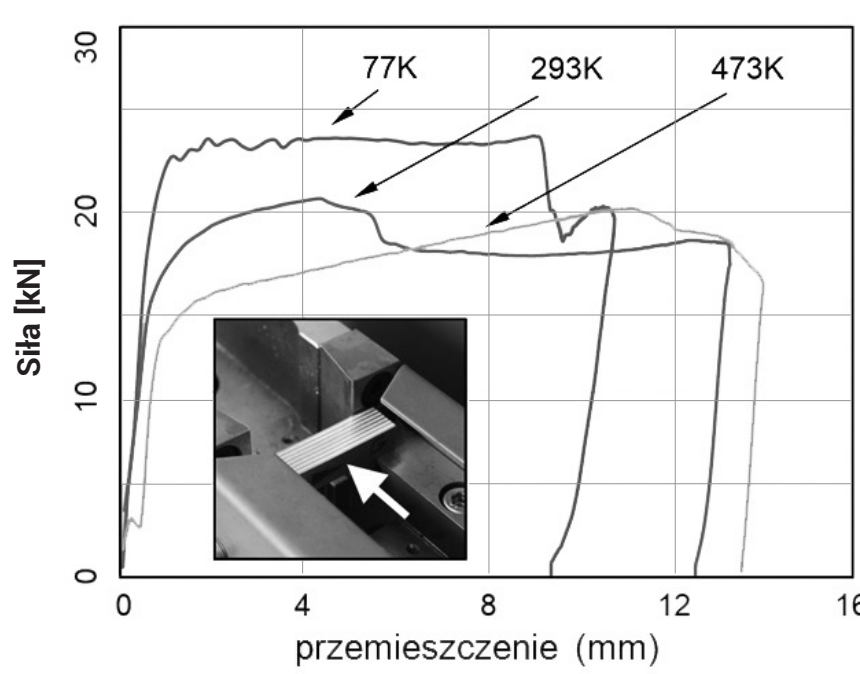

górne powierzchnie (EWD/TD)

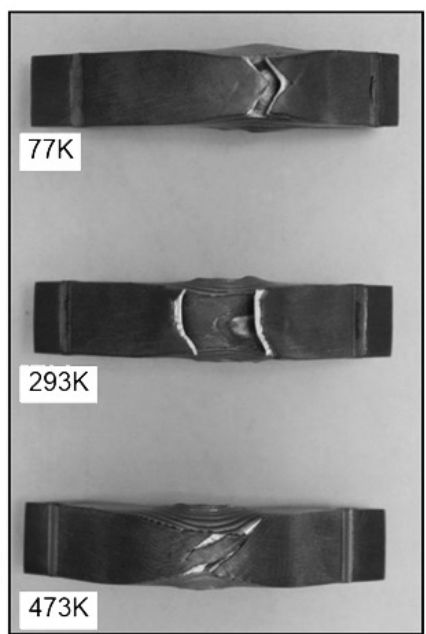

górne boczne

(ND/EWD)

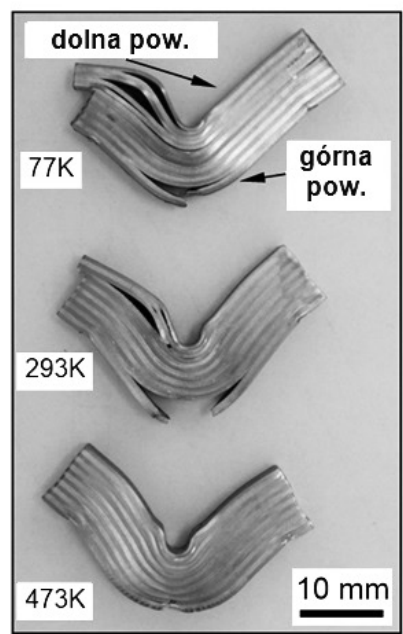

Rys. 4. Krzywe zależności przemieszczenia od siły otrzymanie podczas próby zginania udarowego i próbki po badaniu

Fig. 4. The displacement-force curves obtained during the impact bending test and the post-test sample

\section{Wnioski}

Zastosowane prędkości spajania, $2200 \mathrm{~ms}^{-1}, 2400 \mathrm{~ms}^{-1}$ i $2600 \mathrm{~ms}^{-1}$, doprowadziło do uformowania wielowarstwowego plateru na bazie Ti i Al niewykazującego nieciągłości lub pęknięć. Na przekroju wzdłużnym oraz poprzecznym obserwowano formowanie się niejednorodnej strefy połączenia, która związana była z odmiennym kształtem granicy połączenia, tj. o falistej lub płaskiej charakterystyce, z silnie zróżnicowaną ilością stref przetopień, jak i ich morfologią.

Praca została zrealizowana przy wsparciu finansowym Narodowego Centrum Nauki (NCN), projekt no.: 2016/21/B/ST8/00462

\section{Literatura}

[1] Blazynski T.Z.: Explosive Welding, Forming and Compaction, Applied Science Publishers LTD, New York, 1983

[2] Romberg J., Freudenberger J., Bauder H., Plattner G., Krug H., Holländer F., Scharnweber J., Eschke A., Kühn U., Klauß H., Oertel C-G., Skrotzki W., Eckert J., Schultz L.: Ti/Al Multi-Layered Sheets: Accumulative Roll Bonding (Part A), Metals 6, 2016, pp. 30-44.

[3] Veccio K.S.: Synthetic multifunctional metallic-intermetallic laminate composites, J. of Microscopy 57, 2005, pp. 25-31.

[4] Chulist R., Fronczek D., Szulc Z., Wojewoda-Budka J.: Texture transformations near the bonding zones of the three-layer $\mathrm{Al} / \mathrm{Ti} / \mathrm{Al}$ explosively welded clads, Materials Characterization, 129, 2017, pp. 242-246.
[5] Lazurenko D.V., Bataev I.A., Mali V.I., Bataev A.A., Maliutina lu.N., Lozhkin V.Z., Esikov M.A., Jorge A.M.J.: Explosively welded multilayer Ti-Al composites: Structure and transformation during heat treatment, Materials and Design, 102, 2016, pp. 122-130.

[6] Fronczek D., Wojewoda-Budka J., Chulist R., Sypień A., Kornewa A., Szulc Z., Schell N., Zieba P.: Structural properties if Ti/Al. Clads manufactured by explosive welding and annealing, Materials and Design, 91, 2016, pp. 80-89. 